\title{
Phosphorus-doped silicon nanorod anodes for high power lithium-ion batteries
}

\author{
Chao Yan ${ }^{\ddagger 1}$, Qianru Liu๋1, Jianzhi Gao ${ }^{1}$, Zhibo Yang ${ }^{* 1}$ and Deyan $\mathrm{He}^{2}$
}

Full Research Paper

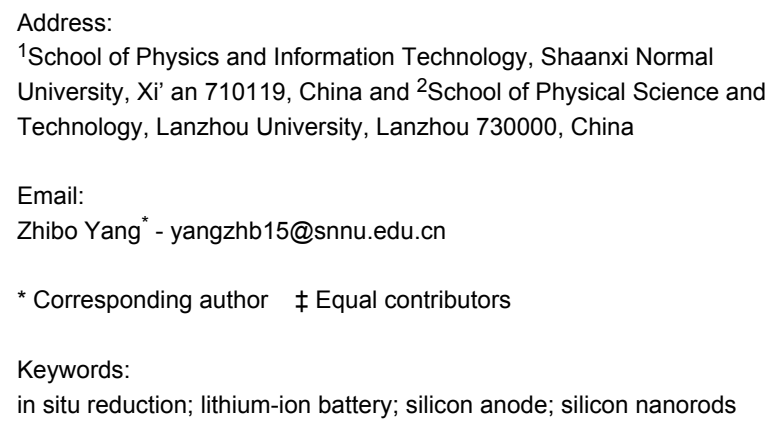

Beilstein J. Nanotechnol. 2017, 8, 222-228. doi:10.3762/bjnano.8.24

Received: 18 October 2016

Accepted: 02 January 2017

Published: 23 January 2017

Associate Editor: N. Motta

(C) 2017 Yan et al.; licensee Beilstein-Institut. License and terms: see end of document.

\begin{abstract}
Heavy-phosphorus-doped silicon anodes were fabricated on $\mathrm{CuO}$ nanorods for application in high power lithium-ion batteries. Since the conductivity of lithiated $\mathrm{CuO}$ is significantly better than that of $\mathrm{CuO}$, after the first discharge, the voltage cut-off window was then set to the range covering only the discharge-charge range of Si. Thus, the $\mathrm{CuO}$ core was in situ lithiated and acts merely as the electronic conductor in the following cycles. The Si anode presented herein exhibited a capacity of $990 \mathrm{mAh} / \mathrm{g}$ at the rate of $9 \mathrm{~A} / \mathrm{g}$ after 100 cycles. The anode also presented a stable rate performance even at a current density as high as $20 \mathrm{~A} / \mathrm{g}$.
\end{abstract}

\section{Introduction}

As one of the most popular secondary power sources, lithiumion batteries (LIBs) are widely used in portable personal electronics, electrical vehicles and grid energy storage because of their high energy and power densities [1,2]. Since the state-ofthe-art commercial LIBs are still far from meeting the ever-increasing demands for such applications, LIBs with higher power and energy density are urgently desired [3]. To some extent, the electrochemical performance of LIBs is mainly determined by the two electrodes. The theoretical capacity of commercially used graphite anodes is only $372 \mathrm{mAh} / \mathrm{g}$, which extremely limits the energy density of LIBs [4]. Thus, much attention has been paid to the pursuit of high performance anode materials to replace graphite. Among them, silicon is considered as the most promising alternative due to its high theoretical capacity of $3579 \mathrm{mAh} / \mathrm{g}$ (forming $\mathrm{Li}_{3.75} \mathrm{Si}$ at room temperature) and low discharge region (the average delithiation voltage is about $0.4 \mathrm{~V}$ ) [4,5]. However, unfortunately, such a high capacity is accompanied by huge volume changes, which could directly lead to cracking and pulverization of electrodes during Li-ion insertion and extraction [6]. Numerous results have proven that fabricating nanostructured Si-based anode materials could effectively accommodate the severe volume changes during cycling $[7,8]$. Lu et al. developed an architecture of flexible silicon and graphene embedded in carbon nanofibers with 
atomic-scale control of the expansion space as anodes for LIBs. Such an anode delivered an electrochemical performance of $2000 \mathrm{mAh} / \mathrm{g}$ at a current density of $700 \mathrm{~mA} / \mathrm{g}$ [5]. Cui et al. designed a yolk-shell-structured $\mathrm{Si}$ anode that has void space between the shell and the particles, allowing for the expansion of $\mathrm{Si}$ without deforming the carbon shell. Such an anode shows a capacity retention of $74 \%$ after 1000 cycles at a rate of C/10 [9]. Yang et al. fabricated a Si-based anode with a core-shell-shell heterostructure of Si nanoparticles as the core with mesoporous carbon and crystalline $\mathrm{TiO}_{2}$ as the double shells. It delivered a high reversible capacity of $1726 \mathrm{mAh} / \mathrm{g}$ over 100 cycles [10]. Among various nanostructured $\mathrm{Si}$ anodes, the electrodes prepared by depositing Si layers directly on nanostructured current collectors always shows an improved battery performance $[7,11]$. In such a stratagem, nanostructured current collectors are generally prepared by carbonization of organics, electrochemical deposition with templates, and reduction of metal oxides, all of which are complicated and costly [7,11-13]. On the other hand, as a semiconductor material, the conductivity of $\mathrm{Si}$ is not high enough for high-power battery applications. Conductive coatings are usually used to enhance the conductivity of Si-based anodes, but the conductivity inside the $\mathrm{Si}$ cannot be changed by this approach, resulting in limited improvements of the high-power performance for Si-based anodes.

In this work, we prepared heavy-phosphorus-doped silicon anodes on $\mathrm{CuO}$ nanorods for high power LIBs. In our experiments, once the voltage cut-off window was set in the range that only covers the discharge-charge range of $\mathrm{Si}$, the conductivity of $\mathrm{CuO}$ nanorods was highly increased by the irreversible reaction with $\mathrm{Li}$-ion during the first discharge, and the lithiated $\mathrm{CuO}$ played the role of an electronic conductor in the following cycles. In addition, the silicon layer was heavily doped by phosphorus and delivered a conductivity as high as $54.0 \mathrm{~S} / \mathrm{cm}$, which is vital for the enhanced high power performance of the obtained Si anode.

\section{Results and Discussion}

The X-ray diffraction patterns shown in Figure 1a proved that the product was $\mathrm{Cu}(\mathrm{OH})_{2}$ (JCPDS 13-0420) after electrochemical etching of $\mathrm{Cu}$. The thermal treatment transformed the $\mathrm{Cu}(\mathrm{OH})_{2}$ completely into $\mathrm{CuO}$ (JCPDS 05-0661). From Figure 1b, it can be seen that the Si layer was totally amorphous.

The structural information of the obtained Si anode was further identified by transmission electron microscopy (TEM). Figure 2a clearly shows that the Si was conformally coated on the $\mathrm{CuO}$ nanorods, resulting in a core-shell nanorod structure. From Figure 2b, it can be seen that the thickness of the Si layer was about $150 \mathrm{~nm}$, and the Si shell was composed of small Si columns with significant free space, which is beneficial to accommodate the large volume changes during Li-ion insertion and extraction. The high-resolution TEM image shown in Figure $2 \mathrm{c}$ provides direct evidence for the amorphous nature of the Si layer. Li-ions diffuse much faster in amorphous than in crystalline materials. The degradation of the Si anode caused by Li-ion insertion and extraction could also be suppressed in amorphous structures since the volume changes in such a material are more homogeneous [14]. From the energy dispersive (EDX) spectra illustrated in Figure 2d (collected in the region indicated by the red box in Figure 2a), it can be concluded that phosphorus atoms exist in the Si layer with an atomic ratio of about 3\%. The existence of phosphorus in the Si layer was further proved by X-ray photoelectron spectroscopy (XPS)
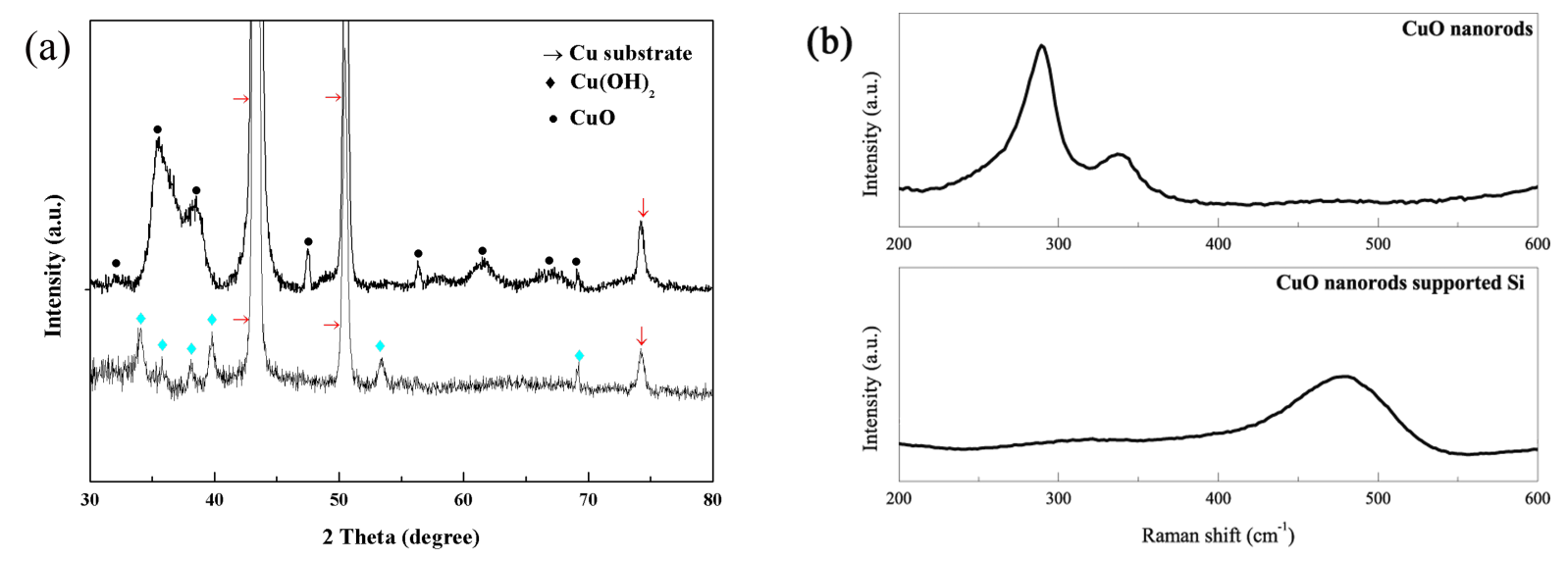

Figure 1: (a) X-ray diffraction patterns of the as-prepared $\mathrm{Cu}(\mathrm{OH})_{2}$ and $\mathrm{CuO}$ nanorods; (b) Raman spectra of the CuO nanorods and Si-coated $\mathrm{CuO}$ nanorods. 


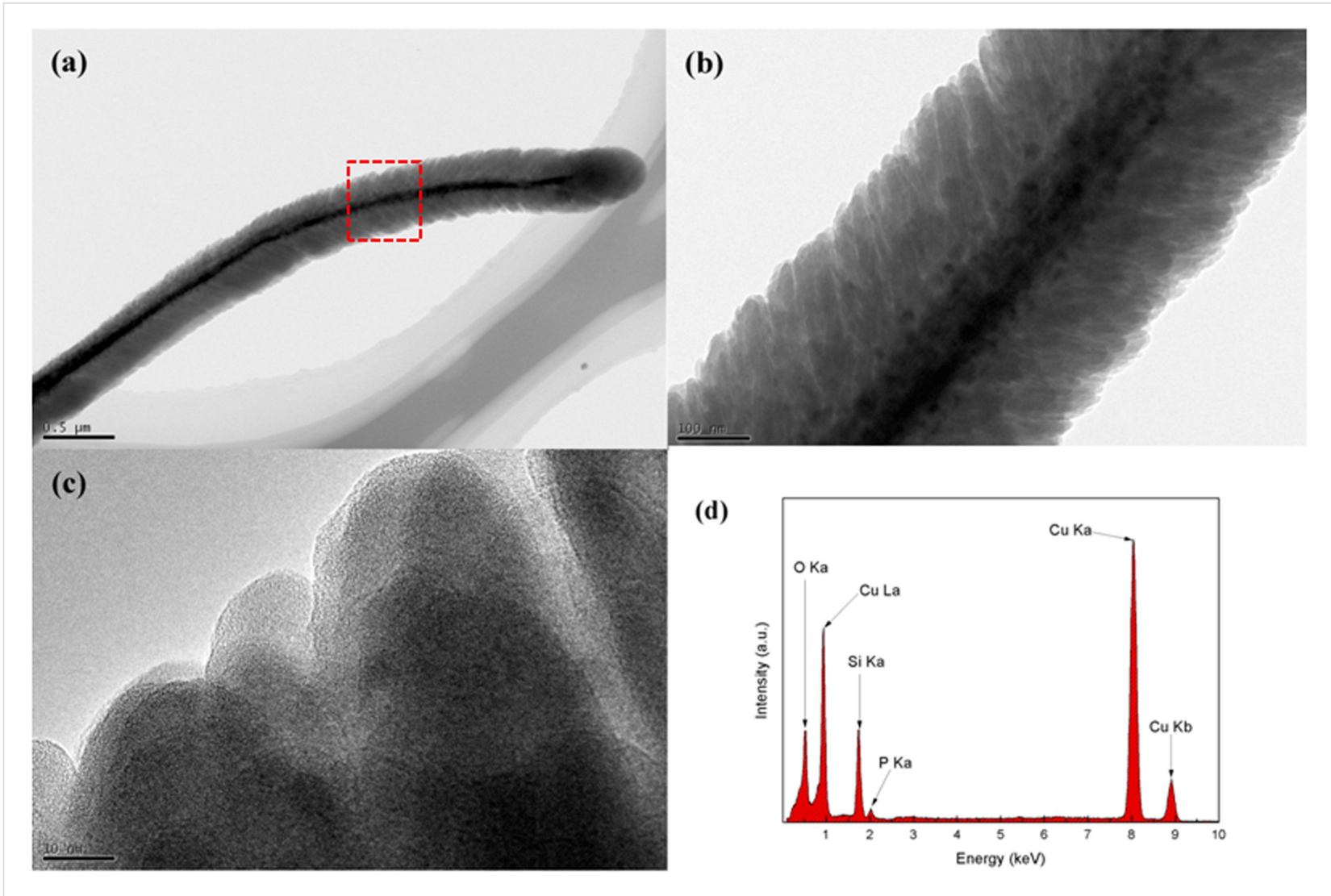

Figure 2: Transmission electron microscopy images for the Si nanorod at (a) low magnification (b) high magnification and (c) high-resolution TEM. (d) Energy dispersive spectra of the Si nanorod section as indicated by the red box in (a).

analysis as shown in Supporting Information File 1, Figure S1. The two peaks at $130.47 \mathrm{eV}$ and $129.74 \mathrm{eV}$ as shown in Supporting Information File 1, Figure $\mathrm{S} 1$ could be ascribed to $\mathrm{P}$ $2 p_{1 / 2}$ and $P 2 p_{3 / 2}$, respectively. Phosphorus-doped Si anodes are assumed to undergo less volume changes than undoped anodes during Li-ion insertion and extraction. This is because some positions are taken by phosphorus and phosphorus is inactive for Li-ion, which means less lithium will be intercalated. Meanwhile, phosphorus doping could highly enhance the conductivity of the Si anode, which is essential for high power performance of LIBs.

To evaluate the conductivity of the as-prepared phosphorusdoped $\mathrm{Si}$, the conductivity measurement was performed at room temperature on a film deposited on a glass substrate under the same experimental conditions described in the experimental section. Before the measurement, coplanar aluminium electrodes with a length of $1 \mathrm{~cm}$ and a spacing of $0.5 \mathrm{~mm}$ were deposited on the Si film by electron-beam evaporation combined with a mask. Then, after an annealing treatment, the conductivity of the film was measured by a nanovoltmeter (Keithley, Model 2182A) combined with a DC current source (Keithley, Model 6221). The results in Figure 3a indicate that the conductivity of the as-prepared phosphorus-doped Si film was as high as $54.0 \mathrm{~S} / \mathrm{cm}\left(1.85 \times 10^{-2} \Omega \mathrm{cm}\right)$, which is close to that of a conductor. The electrochemical impedance spectra (EIS) was measured at the voltages of $2.6 \mathrm{~V}$ and $0.7 \mathrm{~V}$ and the Nyquist plots are shown in Figure 3b. At a voltage of $2.7 \mathrm{~V}$, both $\mathrm{CuO}$ and $\mathrm{Si}$ were not lithiated and $\mathrm{CuO}$ could be totally lithiated at $0.7 \mathrm{~V}$. The reduction in the semicircular nature in the Nyquist plot characteristics shown in Figure $3 \mathrm{~b}$ indicated that the charge transfer resistance of the obtained $\mathrm{Si}$ anode at $0.7 \mathrm{~V}$ was much lower than that at $2.6 \mathrm{~V}$. According to the equation $\mathrm{CuO}+2 \mathrm{Li}^{+}+2 \mathrm{e}^{-} \rightarrow \mathrm{Cu}+\mathrm{Li}_{2} \mathrm{O}$, this could be ascribed to the reaction of $\mathrm{CuO}$ with lithium, which transformed insulative $\mathrm{CuO}$ into conductive $\mathrm{Cu}$. Thus, if the lithiation reaction of $\mathrm{CuO}$ is irreversible, the $\mathrm{CuO}$ core part could be used as an electronic conductor. For such purpose, the voltage cut-off window was set in the range of $0.02-0.7 \mathrm{~V}$, which avoids the discharge-charge voltage areas of $\mathrm{CuO}$ and results in the irreversible lithiation reaction of $\mathrm{CuO}$.

The galvanostatic discharge-charge profiles given in Figure 4a indicate that the discharge voltage signature of $\mathrm{CuO}$ disappears after the first discharge when the voltage cut-off window was set in the range between $0.02-0.7 \mathrm{~V}$, which was further proven 
(a)

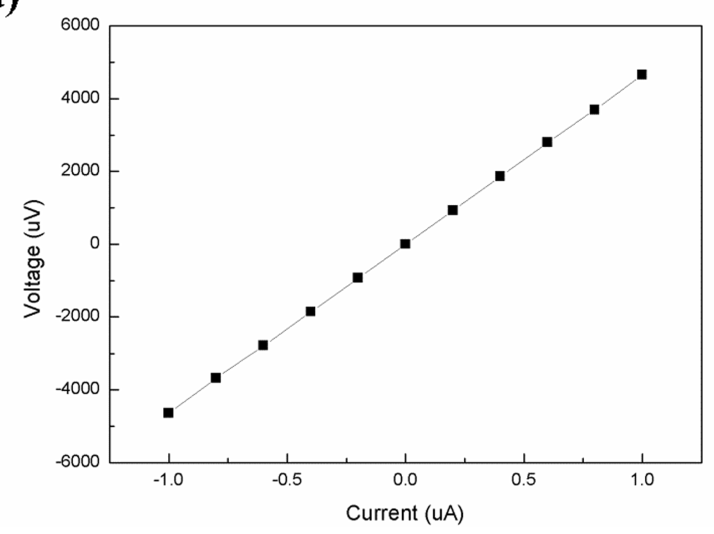

(b)

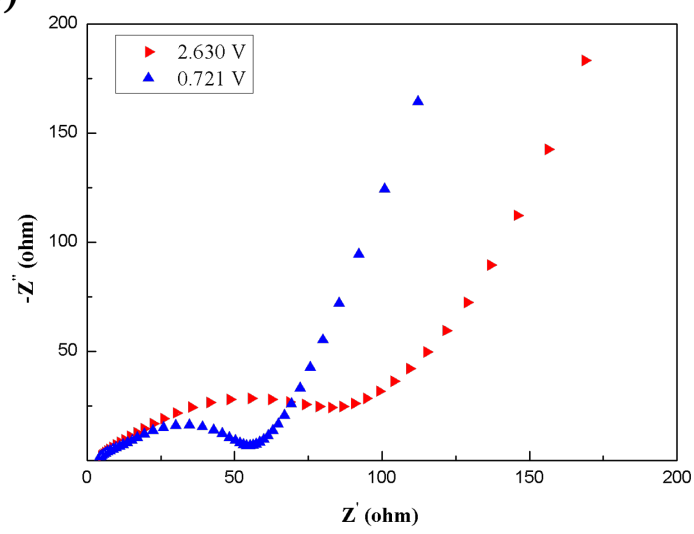

Figure 3: (a) $I-V$ curve of the as-prepared Si film on glass substrate. (b) Nyquist plots of the Si electrode at $2.630 \mathrm{~V}$ and $0.721 \mathrm{~V}$.

by the cyclic voltammetry (CV) curves shown in Figure $4 \mathrm{~b}$. From Figure 4a and Figure 4b, it can be concluded that $\mathrm{CuO}$ was irreversibly reduced to a conductive mixture of $\mathrm{Cu}$ and $\mathrm{Li}_{2} \mathrm{O}$ (according to the equation $\mathrm{CuO}+2 \mathrm{Li}^{+}+2 \mathrm{e}^{-} \rightarrow \mathrm{Cu}+$ $\left.\mathrm{Li}_{2} \mathrm{O}\right)$ in the first discharge, and by setting the voltage cut-off window in the range only covering the discharge-charge range of $\mathrm{Si}$, the core part of the nanorods could be kept in the conductive mixture state, working only as an electronic conductor in the following cycles. To test the cycling stability of the resulting $\mathrm{Si}$ anodes, the anodes were cycled at the current densities of $2 \mathrm{~A} / \mathrm{g}, 5 \mathrm{~A} / \mathrm{g}$ and $9 \mathrm{~A} / \mathrm{g}$ (a current density of $200 \mathrm{~mA} / \mathrm{g}$ was performed in the first three cycles). From the results shown in Figure $4 \mathrm{c}$, it can be seen that the anode delivered a discharge capacity of $1900 \mathrm{mAh} / \mathrm{g}$ in the first discharge under the current density of $2 \mathrm{~A} / \mathrm{g}$, and such a capacity slowly decreased to $1200 \mathrm{mAh} / \mathrm{g}$ after 100 cycles. For the current density of $9 \mathrm{~A} / \mathrm{g}$, a reversible capacity of $1100 \mathrm{mAh} / \mathrm{g}$ was obtained in the first cycle, which delivered a capacity retention of $90 \%$ after 100 cycles. The capacity reduction in the initial 10 cycles can be ascribed to the polarization and peel off of the active Si. After 10 cycles, the structure of the electrodes was stabilized under the test rates, and the activation started to play the leading role in the Si anode. Thus, the increased capacity after the 10th cycle could be ascribed to the activation of the anode. At the same time, it is noteworthy that the enormous specific capacity of Si will bring great changes regarding anode-cathode matching. For the practical application of Si-based anodes, the state-of-the-art commercial cathodes cannot deliver a suitable matching with the Si anode. Thus, the search for suitable cathodes should be of high priority for researchers of Si-based anodes. To match the practical use of Si-based anodes, sulfur $(1675 \mathrm{mAh} / \mathrm{g})$ and/or transition-metal-sulphides might be the potential candidates for the state-of-the-art commercial cathodes [15]. In addition, the rate performance of the resulting $\mathrm{Si}$ anode was tested and the result is illustrated as Figure 4d. The current density for the test was set at $0.2 \mathrm{~A} / \mathrm{g}$ to $20 \mathrm{~A} / \mathrm{g}$. The prepared $\mathrm{Si}$ anode delivered stable cycling performance under all test conditions. It is noteworthy that even under a current density as high as $20 \mathrm{~A} / \mathrm{g}$, the $\mathrm{Si}$ anode still presented a specific capacity of $380 \mathrm{mAh} / \mathrm{g}$. The galvanostatic discharge/charge profiles of Figure $4 \mathrm{~d}$ are presented in Figure $4 \mathrm{e}$. It can be seen that the voltage of the discharge region of the $\mathrm{Si}$ anode obviously declines as the test rates increase. At the same time, the voltage of the charge region increases. This could be ascribed to the kinetic effects and polarization of the electrode materials, which is a common phenomenon for anode materials of LIBs $[16,17]$.

The improved lithium storage performance can be ascribed to the unique nanostructure of the as-prepared Si anode. The morphology of the prepared Si anode and the precursors were investigated by SEM. Figure 5a and Figure $5 \mathrm{~b}$ show the $\mathrm{Cu}(\mathrm{OH})_{2}$ and $\mathrm{CuO}$ nanorods, respectively. It can be seen that the nanorods are crosslinked and formed a stable three-dimensional network. A comparison between the $\mathrm{Cu}(\mathrm{OH})_{2}$ and $\mathrm{CuO}$ nanorods indicated that the thermal treatment barely changed the network and the diameter for both of $\mathrm{Cu}(\mathrm{OH})_{2}$ and $\mathrm{CuO}$ nanorods, which was about $150 \mathrm{~nm}$. The morphology of the obtained $\mathrm{Si}$ anode is illustrated in Figure 5c. The Si anode inherited the nanorod structure of the $\mathrm{CuO}$ precursor and presented a conformal Si coating. Comparing the insets in Figure $5 \mathrm{~b}$ and Figure $5 \mathrm{c}$, it can be estimated that the thickness of the Si layer was about $150 \mathrm{~nm}$, which was in accordance with the TEM results. From the cross-section SEM images shown in Supporting Information File 1, Figure S2, the thickness of the active Si nanorods was about $10 \mu \mathrm{m}$, which is $29 \%$ of the overall thickness of the anode (including the current collector). To verify the structural transformation of the $\mathrm{Si}$ anode after cycling, a battery after 50 cycles at a rate of $2 \mathrm{~A} / \mathrm{g}$ was disassembled. The $\mathrm{Si}$ anode was washed thoroughly with deionized water and ethanol 
(a)

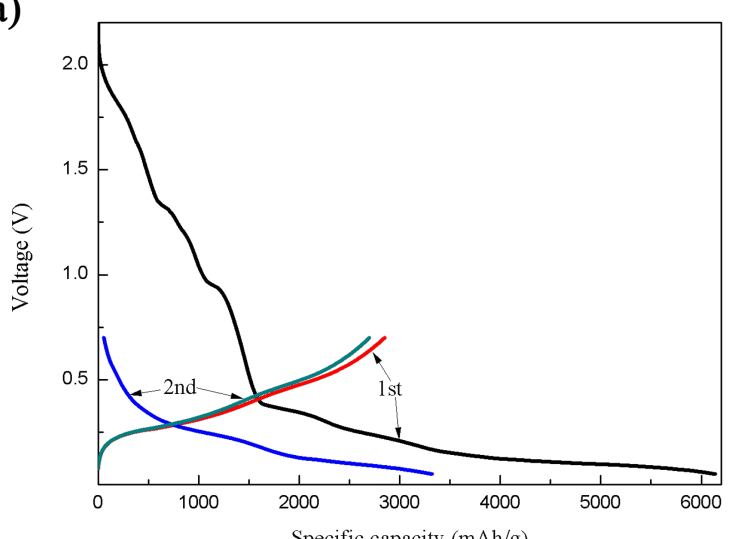

(c)

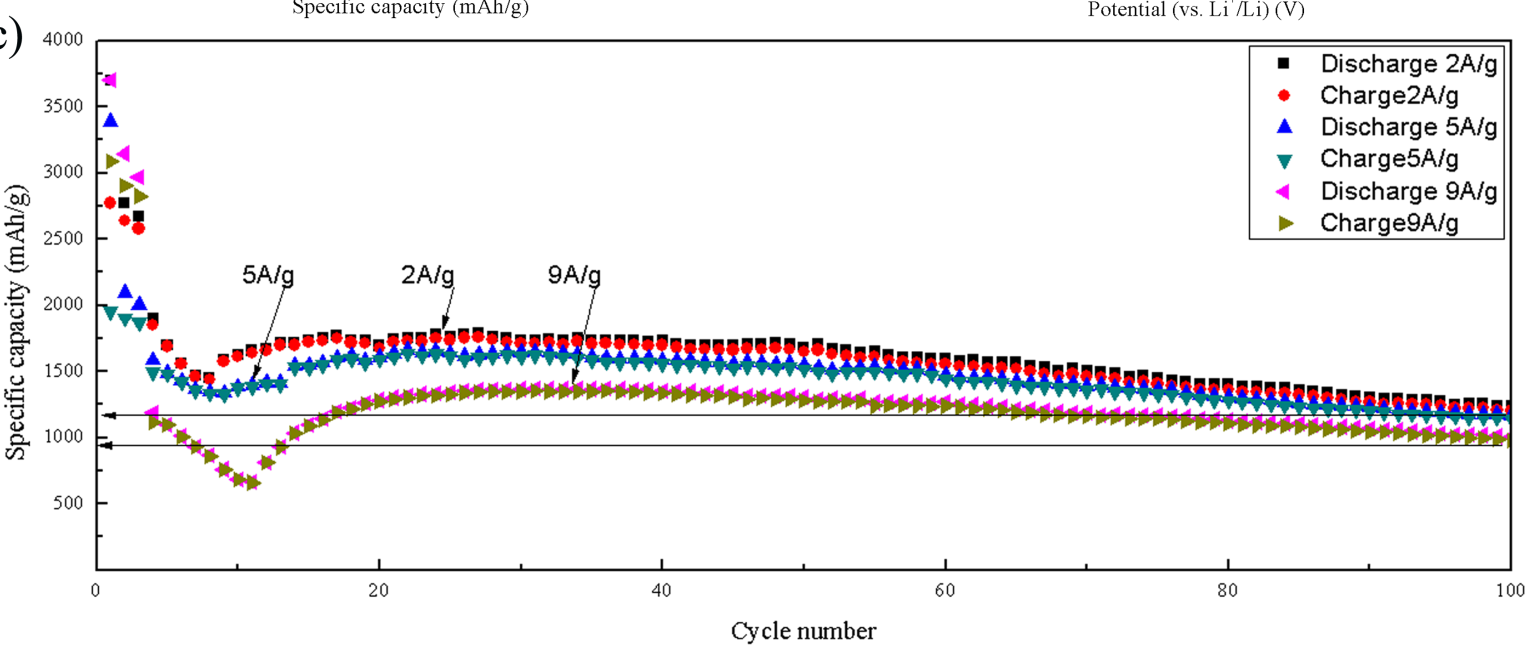

(b)

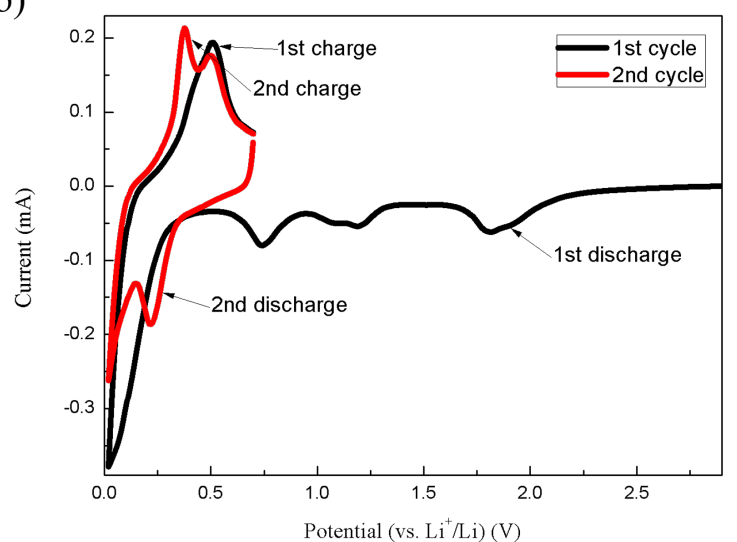

(d)

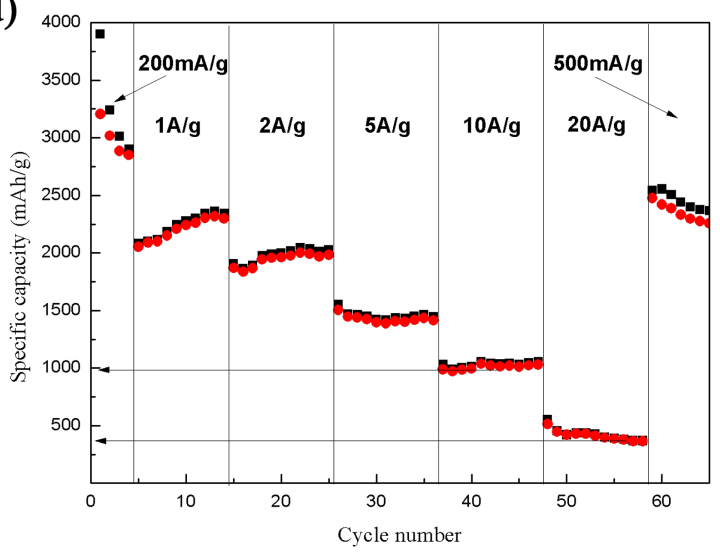

(e)

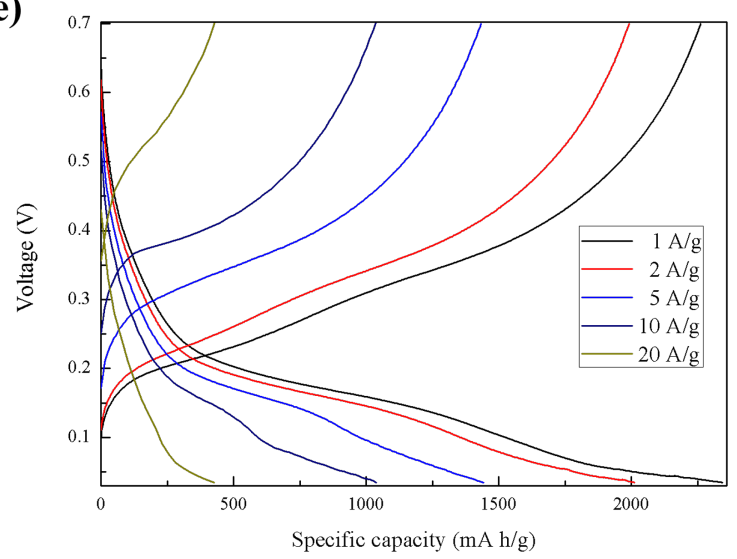

Figure 4: Electrochemical performance of the Si anode. (a,b) Galvanostatic discharge-charge profiles and CV curves for the initial two cycles. (c) Cycling at $2 \mathrm{~A} / \mathrm{g}, 5 \mathrm{~A} / \mathrm{g}$ and $9 \mathrm{~A} / \mathrm{g}$, (d) rate performance, and (e) galvanostatic discharge-charge profiles of Figure 4d.

to remove the $\mathrm{Li}_{2} \mathrm{O}$ and solid electrolyte interphase layer. The morphology of the cycled Si anode is shown in Figure 5d. Here it is evident that the electrode remained as a nanorod array after 50 cycles without any obvious structural degradation, which may be responsible for the improved lithium storage performance. Based on the above discussion, the improvement of the electrochemical performance of the obtained Si anode could be ascribed to the following factors. First, the transport paths for electrons and Li ions were significantly shortened in the nanorod core-shell-structured electrode. Then, the transport velocity for electrons and Li ions was enhanced by the phosphorus doping for amorphous $\mathrm{Si}$ and the $\mathrm{Cu}$ conductive core parts of the nanorods, which was directly connected to the substrate. Finally, the free space between the small amorphous Si 


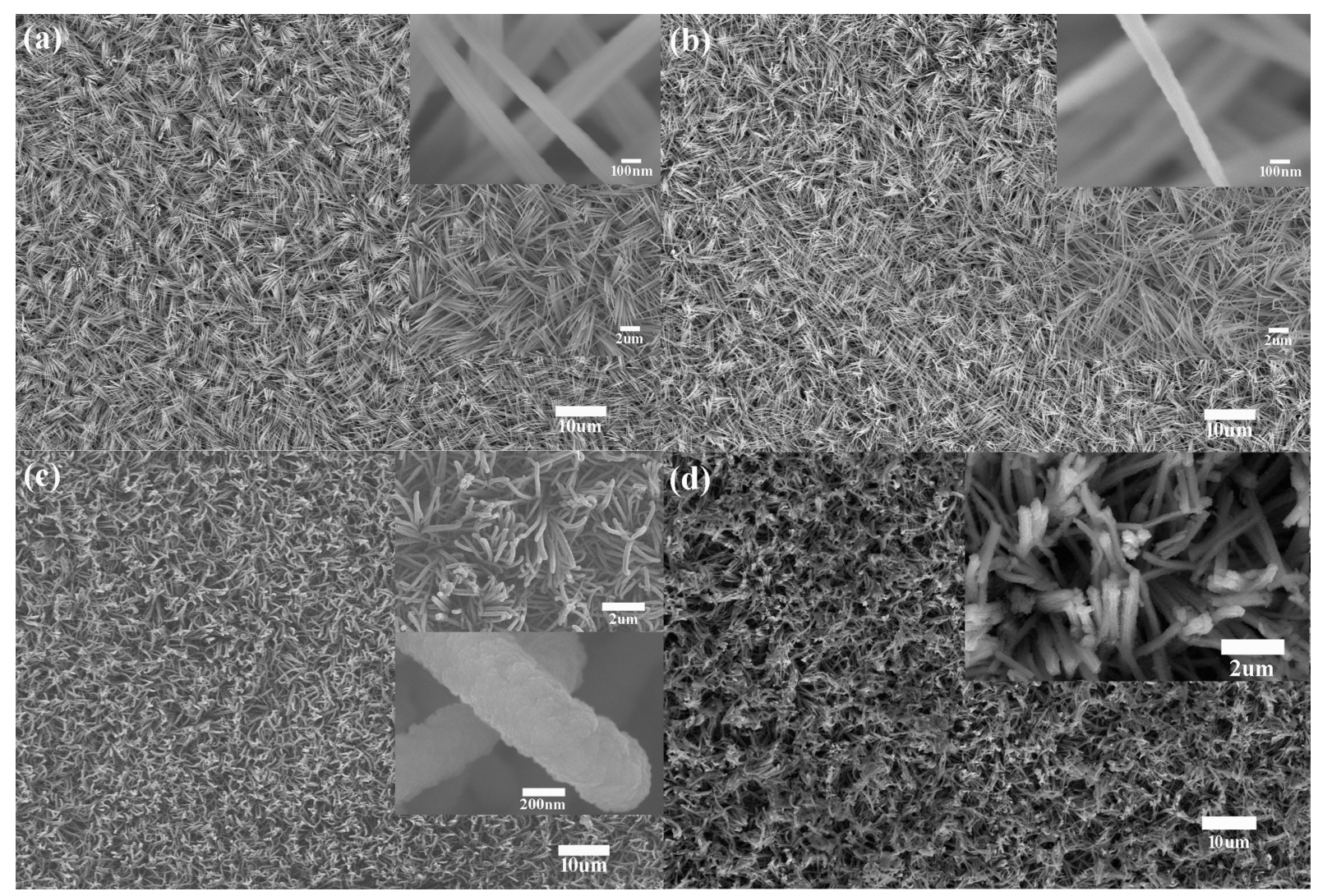

Figure 5: Top view SEM images of the (a) $\mathrm{Cu}(\mathrm{OH})_{2}$ nanorods, (b) CuO nanorods, and (c) Si anode supported on $\mathrm{CuO}$ nanorods and (d) $\mathrm{Si}$ anode after 50 cycles.

columns and the nanorods provided enough space to accommodate the volume change caused by Li-ion insertion and extraction.

\section{Conclusion}

In summary, we have successfully fabricated a phosphorusdoped $\mathrm{Si}$ anode which delivered improved lithium storage performance. By limiting the voltage cut-off window to the range only covering the discharge-charge range for $\mathrm{Si}$, the $\mathrm{CuO}$ core part could be in situ transformed into a conductive mixture of $\mathrm{Cu}$ and $\mathrm{Li}_{2} \mathrm{O}$, which could be used as the electronic collector for the doped Si anode. Such experimental design is promising for simplifying the fabrication procedure of nanostructured current collectors for Si anodes.

\section{Experimental}

\section{Sample preparation and characterization}

The $\mathrm{CuO}$ nanorods were obtained by dehydration treatment of $\mathrm{Cu}(\mathrm{OH})_{2}$ nanorods at $150{ }^{\circ} \mathrm{C}$ in vacuum for $10 \mathrm{~min}$. The $\mathrm{Cu}(\mathrm{OH})_{2}$ nanorods were prepared by the galvanostatic electrochemical anodization of a $\mathrm{Cu}$ plate in a two-electrode system via a DC power supply (ITECH IT6123B). Typically, a copper foil $(20 \mathrm{~mm} \times 20 \mathrm{~mm} \times 25 \mu \mathrm{m}, 99 \%$, back side covered by insulating type) was pretreated in alcohol and then used as the anode. The cathode was a graphite rod with $55 \mathrm{~mm}$ length and $5 \mathrm{~mm}$ diameter, and was kept $25 \mathrm{~mm}$ away from the anode. The anodization process was carried out in $0.8 \mathrm{M} \mathrm{NaOH}$ aqueous solution, and a constant current of $6 \mathrm{~mA}$ was applied at room temperature. After $12 \mathrm{~min}$, the $\mathrm{Cu}$ foil was taken out and washed with deionized water thoroughly. The $\mathrm{Si}$ anode was fabricated through deposition of a heavy-phosphorus-doped $\mathrm{Si}$ layer directly onto the $\mathrm{CuO}$ nanorods via a radio frequency, capacitively coupled, plasma-enhanced chemical vapor deposition (PECVD) device. Typically, the source gas for PECVD was silane (10\%, diluted with hydrogen) with a flow rate of $50 \mathrm{sccm}$ mixed with phosphine $(5 \%$, diluted with hydrogen) with a flow rate of $5 \mathrm{sccm}$. The deposition pressure and substrate temperature were $80 \mathrm{~Pa}$ and $150^{\circ} \mathrm{C}$, respectively.

The structural and morphological information of the resultant materials were characterized by X-ray diffraction (Rigaku D/ Max-2400, Cu Ka radiation), micro-Raman spectrometry (Jobin-Yvon, LabRAM HR800, $532 \mathrm{~nm}$ radiation), field emission scanning electron microscopy (FEI, Nova Nano SEM 450), transmission electron microscopy (FEI, Tecnai G2 F30) and 
X-ray photoelectron spectrometry (VG Scientific, ESCALAB MKII, Mg Ka radiation).

\section{Electrode preparation and electrochemical characterization}

CR 2032 coin type half cells were assembled in an argon-filled glove box (Mikrouna, Super1220, $\mathrm{H}_{2} \mathrm{O}$ and $\mathrm{O}_{2}<1 \mathrm{ppm}$ ) for electrochemical characterization. The obtained $\mathrm{Si}$ anode was directly used as the work electrode without any conductive additive and binder. Lithium foil and Celgard 2320 were used as the counter electrode and separator membrane, respectively. The electrolyte was $1 \mathrm{M} \mathrm{LiPF}_{6}$ dissolved in ethylene carbonate (EC) and diethyl carbonate (DEC) (1:1 in volume). Galvanostatic cycling was carried out on a multichannel cell test instrument (Neware BTS-610). Cyclic voltammogramms (CV) and electrochemical impedance spectra (EIS) were measured using an electrochemical workstation (Metrohm, Autolab302N). The voltage cut-off window for galvanostatic cycling and $\mathrm{CV}$ was set in the range of $0.02-0.7 \mathrm{~V}$. CV tested at a scan rate of $0.1 \mathrm{mV} / \mathrm{s}$. The active mass was evaluated by measuring the mass difference before and after Si deposition through an analytical balance (Mettler, MS105DU, sensitivity of $0.01 \mathrm{mg}$ ). The mean loading mass density of Si was about $0.26 \mathrm{mg} / \mathrm{cm}^{2}$.

\section{Supporting Information}

\section{Supporting Information File 1}

Additional figures.

[http://www.beilstein-journals.org/bjnano/content/ supplementary/2190-4286-8-24-S1.pdf]

\section{Acknowledgements}

The project was financially supported by the Fundamental Research Funds for the Central Universities (Grant no. GK201603018 and GK201603013).

\section{References}

1. Scrosati, B.; Hassoun, J.; Sun, Y.-K. Energy Environ. Sci. 2011, 4, 3287-3295. doi:10.1039/C1EE01388B

2. Cui, L.-F.; Hu, L.; Choi, J. W.; Cui, Y. ACS Nano 2010, 4, 3671-3678. doi:10.1021/NN100619M

3. Yoo, H.-D.; Markevich, E.; Salitra, G.; Sharon, D.; Aurbach, D. Mater. Today 2014, 17, 110-121. doi:10.1016/J.MATTOD.2014.02.014

4. Kim, H.; Lee, E.-J.; Sun, Y.-K. Mater. Today 2014, 17, 285-297. doi:10.1016/J.MATTOD.2014.05.003

5. Zhu, J.; Wang, T.; Fan, F.; Mei, L.; Lu, B. ACS Nano 2016, 10 , 8243-8251. doi:10.1021/ACSNANO.6B04522

6. Kim, S.-J.; Kim, M.-C.; Han, S.-B.; Lee, G.-H.; Choe, H.-S.; Kwak, D.-H.; Choi, S.-Y.; Son, B.-G.; Shin, M.-S.; Park, K.-W. Nano Energy 2016, 27, 545-553. doi:10.1016/J.NANOEN.2016.08.012

7. Xiao, Q.; Fan, Y.; Wang, X.; Susantyoko, R. A.; Zhang, Q. Energy Environ. Sci. 2014, 7, 655-661. doi:10.1039/C3EE43350A
8. Wu, H.; Chan, G.; Choi, J. W.; Ryu, I.; Yao, Y.; McDowell, M. T.; Lee, S. W.; Jackson, A.; Yang, Y.; Hu, L.; Cui, Y. Nat. Nanotechnol. 2012, 7, 310-315. doi:10.1038/NNANO.2012.35

9. Liu, N.; Wu, H.; McDowell, M. T.; Yao, Y.; Wang, C.; Cui, Y. Nano Lett. 2012, 12, 3315-3321. doi:10.1021/NL3014814

10. Luo, W.; Wang, Y.; Wang, L.; Jiang, W.; Chou, S.-L.; Dou, S. X.; Liu, H. K.; Yang, J. ACS Nano 2016, 10, 10524-10532. doi:10.1021/ACSNANO.6B06517

11. Zhang, S.; Du, Z.; Lin, R.; Jiang, T.; Liu, G.; Wu, X. Adv. Mater. 2010, 22, 5378-5382. doi:10.1002/ADMA.201003017

12. Cao, F.-F.; Deng, J.-W.; Xin, S.; Ji, H.-X.; Schmidt, O. G.; Wan, L.-J.; Guo, Y.-G. Adv. Mater. 2011, 23, 4415-4420. doi:10.1002/ADMA.201102062

13. Yang, Z.; Wang, D.; Li, F.; Yue, H.; Liu, D.; Li, X.; Qiao, L.; He, D. Mater. Lett. 2014, 117, 58-61. doi:10.1016/j.matlet.2013.12.001

14. Yan, C.; Xi, W.; Si, W.; Deng, J.; Schmidt, O.-G. Adv. Mater. 2013, 25 , 539-544. doi:10.1002/adma.201203458

15. Juhl, A. C.; Schneider, A.; Ufer, B.; Brezesinski, T.; Janek, J.; Fröba, M. Beilstein J. Nanotechnol. 2016, 7, 1229-1240. doi:10.3762/BJNANO.7.114

16. Wu, H.; Du, N.; Shi, X.; Yang, D. J. Power Sources 2016, 331, 76-81. doi:10.1016/J.JPOWSOUR.2016.09.046

17. Wang, X.; Yang, Z.; Sun, X.; Li, X.; Wang, D.; Wang, P.; He, D. J. Mater. Chem. 2011, 21, 9988-9990. doi:10.1039/C1JM11490E

\section{License and Terms}

This is an Open Access article under the terms of the Creative Commons Attribution License (http://creativecommons.org/licenses/by/4.0), which permits unrestricted use, distribution, and reproduction in any medium, provided the original work is properly cited.

The license is subject to the Beilstein Journal of Nanotechnology terms and conditions: (http://www.beilstein-journals.org/bjnano)

The definitive version of this article is the electronic one which can be found at: doi:10.3762/bjnano.8.24 